Percutaneous coronary angioplasty versus coronary artery bypass grafting in treatment of unprotected left main stenosis (NOBLE) : a prospective, randomised, open-label, non-inferiority trial

\author{
Makikallio, Timo
}

2016-12-03

Makikallio , T, Holm , N R , Lindsay, M , Spence , M S, Erglis , A, Menown , I B A, Trovik , T , Eskola , M , Romppanen , H , Kellerth , T , Ravkilde , J , Jensen , L O , Kalinauskas , G , Linder , R B A , Pentikainen, M , Hervold , A , Banning , A , Zaman , A , Cotton , J , Eriksen , $E$, Margus , S , Sorensen , H T , Nielsen , P H , Niemela , M , Kervinen , K, Lassen , J F , Maeng, M , Oldroyd , K, Berg , G, Walsh , S J , Hanratty , C G , Kumsars , I, Stradins , P , Steigen , T K , Frobert , O Graham , A N J , Endresen , P C , Corbascio , M , Kajander , O, Trivedi , U , Hartikainen , J , Anttila , V , Hildick-Smith , D , Thuesen , L , Christiansen , E H \& NOBLE Study Investigators 2016 , ' Percutaneous coronary angioplasty versus coronary artery bypass grafting in treatment of unprotected left main stenosis (NOBLE) : a prospective, randomised, open-label, non-inferiority trial ' , Lancet, vol. 388 , no. 10061 , pp. 2743-2752 . https://doi.org/10.1016/S0140-6736(16)32052-9

http://hdl.handle.net/10138/230021

https://doi.org/10.1016/S0140-6736(16)32052-9

publishedVersion

Downloaded from Helda, University of Helsinki institutional repository.

This is an electronic reprint of the original article.

This reprint may differ from the original in pagination and typographic detail.

Please cite the original version. 


\title{
Percutaneous coronary angioplasty versus coronary artery bypass grafting in treatment of unprotected left main stenosis (NOBLE): a prospective, randomised, open-label, non-inferiority trial
}

\author{
Timo Mäkikallio, Niels R Holm, Mitchell Lindsay, MarkS Spence, Andrejs Erglis, lan B A Menown, Thor Trovik, Markku Eskola, Hannu Romppanen, \\ Thomas Kellerth, Jan Ravkilde, Lisette O Jensen, Gintaras Kalinauskas, Rikard B A Linder, Markku Pentikainen, Anders Hervold, Adrian Banning, \\ Azfar Zaman, Jamen Cotton, Erlend Eriksen, Sulev Margus, Henrik T Sørensen, Per H Nielsen, Matti Niemelä, Kari Kervinen, Jens F Lassen, Michael Maeng, \\ Keith Oldroyd, GeoffBerg, Simon JWalsh, Colm G Hanratty, Indulis Kumsars, Peteris Stradins, Terje K Steigen, Ole Fröbert, Alastair NJ Graham, \\ Petter CEndresen, Matthias Corbascio, Olli Kajander, Uday Trivedi, Juha Hartikainen, Vesa Anttila, David Hildick-Smith, LeifThuesen, \\ Evald H Christiansen, for the NOBLE study investigators*
}

\section{Summary}

Background Coronary artery bypass grafting (CABG) is the standard treatment for revascularisation in patients with left main coronary artery disease, but use of percutaneous coronary intervention (PCI) for this indication is increasing. We aimed to compare PCI and CABG for treatment of left main coronary artery disease.

Methods In this prospective, randomised, open-label, non-inferiority trial, patients with left main coronary artery disease were enrolled in 36 centres in northern Europe and randomised 1:1 to treatment with PCI or CABG. Eligible patients had stable angina pectoris, unstable angina pectoris, or non-ST-elevation myocardial infarction. Exclusion criteria were ST-elevation myocardial infarction within $24 \mathrm{~h}$, being considered too high risk for CABG or PCI, or expected survival of less than 1 year. The primary endpoint was major adverse cardiac or cerebrovascular events (MACCE), a composite of all-cause mortality, non-procedural myocardial infarction, any repeat coronary revascularisation, and stroke. Non-inferiority of PCI to CABG required the lower end of the 95\% CI not to exceed a hazard ratio (HR) of 1.35 after up to 5 years of follow-up. The intention-to-treat principle was used in the analysis if not specified otherwise. This trial is registered with ClinicalTrials.gov identifier, number NCT01496651.

Findings Between Dec 9, 2008, and Jan 21, 2015, 1201 patients were randomly assigned, 598 to PCI and 603 to CABG and 592 in each group entered analysis by intention to treat. Kaplan-Meier 5 year estimates of MACCE were $29 \%$ for PCI (121 events) and 19\% for CABG (81 events), HR 1.48 (95\% CI 1.11-1.96), exceeding the limit for non-inferiority, and CABG was significantly better than PCI $(\mathrm{p}=0.0066)$. As-treated estimates were $28 \%$ versus $19 \%(1 \cdot 55,1 \cdot 18-2 \cdot 04$, $\mathrm{p}=\mathbf{0}$.0015). Comparing PCI with CABG, 5 year estimates were $12 \%$ versus $9 \%(1 \cdot 07,0 \cdot 67-1 \cdot 72, p=0 \cdot 77)$ for all-cause mortality, $7 \%$ versus $2 \%(2 \cdot 88,1 \cdot 40-5 \cdot 90, p=0 \cdot 0040)$ for non-procedural myocardial infarction, $16 \%$ versus $10 \%$ $(1 \cdot 50,1 \cdot 04-2 \cdot 17, p=0 \cdot 032)$ for any revascularisation, and $5 \%$ versus $2 \%(2 \cdot 25,0 \cdot 93-5 \cdot 48, p=0 \cdot 073)$ for stroke.

Interpretation The findings of this study suggest that CABG might be better than PCI for treatment of left main stem coronary artery disease.

Funding Biosensors, Aarhus University Hospital, and participating sites.

\section{Introduction}

Treatment of unprotected left main coronary artery disease with percutaneous coronary intervention (PCI) has increased rapidly during the past decade, following the favourable results of randomised trials ${ }^{1-4}$ and observational registry studies comparing PCI and coronary artery bypass grafting (CABG)..$^{5-9}$ At present, both options are used to treat left main coronary artery disease. ${ }^{10}$ Present guidelines recommend PCI in patients with left main coronary artery disease and coronary pathology favourable to PCI (ie, in the absence of complex and diffuse lesions). ${ }^{10}$ The guidelines are based primarily on the prespecified and powered subgroup of 705 patients with left main coronary artery disease in the
SYNTAX trial, ${ }^{11-12}$ which compared PCI and the drug-eluting Taxus stent with CABG in patients with three-vessel or left main coronary artery disease. The guidelines also refer to the findings of the randomised trials LE MANS (100 patients), ${ }^{1}$ PRECOMBAT (600 patients), ${ }^{2}$ and Boudriot and colleagues (201 patients) trials, which included patients with left main coronary artery stenosis. In the randomised trials, the noninferiority margin was wide, because of relatively small patient sample sizes, and thus the trials were not powered to definitively determine the best treatment for unprotected left main coronary artery disease.

In the NOBLE trial, we postulated that PCI with drugeluting stents would produce non-inferior clinical results
Lancet 2016; 388: 2743-52

Published Online October 31, 2016 http://dx.doi.org/10.1016/ S0140-6736(16)32052-9

This online publication has been corrected. The corrected version first appeared at thelancet.com on November 2, 2016

See Comment page 2715

*NOBLE study investigators are listed in the appendix

Department of Cardiology, Oulu University Hospital, Oulu, Finland (T Mäkikallio MD,

M Niemelä PhD,

K Kervinen PhD); Department of Cardiology, Aarhus University Hospital, Skejby, Aarhus, Denmark ( N R Holm MD, J F Lassen PhD, $M$ Maeng PhD,

E H Christiansen PhD); Department of Cardiology, Golden Jubilee National Hospital, Clydebank, Scotland (M Lindsay MD, Professor K Oldroyd MD G Berg MD); Belfast Heart Centre, Belfast Trust, Belfast, Northern Ireland (M Spence MD, S J Walsh MD C G Hanratty MD, A N J Graham MD); Latvia Centre of Cardiology, Paul Stradins Clinical Hospital, Riga, Latvia (Professor A Erglis PhD, I Kumsars MD, P Stradins PhD); Craigavon Cardiac Centre, Craigavon, Northern Ireland (I B A Menown FRCP); Department of Cardiology, University of Northern Norway, Tromsø, Norway (T Trovik PhD, T K Steigen PhD); Department of Cardiovascular Surgery, University of Northern Norway, Tromsø, Norway (PC Endresen PhD), 


\begin{tabular}{|c|c|}
\hline Heart & \\
\hline Univer & Research in context \\
\hline $\begin{array}{r}\text { Finland (M Eskola PhD, } \\
\text { O Kajander PhD); Heart Center, }\end{array}$ & Evidence before this study \\
\hline Kuopio University Hospital, & We searched PubMed for randomised trials comparing \\
\hline Kuopio, Finland & percutaneous coronary intervention $(\mathrm{PCl})$ with coronary artery \\
\hline $\begin{array}{l}\text { (H Romppanen PhD, } \\
\text { Prof J Hartikainen PhD); }\end{array}$ & bypass grafting ( $\mathrm{CABG}$ ) in the treatment of left main coronary \\
\hline Department of Cardiology, & artery disease with the search terms "percutaneous coronary \\
\hline Örebro University & intervention", "coronary artery byp \\
\hline rebro, Sweden ( $T$ Kellerth MD, & artery bypass grafting", "randomised", or "randomized", \\
\hline $\begin{array}{l}\text { O Fröbert PhD); Department of } \\
\text { Cardiology, Aalborg University }\end{array}$ & published after the introduction of drug-eluting stents between \\
\hline Hospital, Aalborg, Denmark & Jan 1, 2003, and Sept 1, 2016. We identified four randomised \\
\hline kilde DMSc, & trials. Three trials were underpowered for clinical endpoints and \\
\hline LThuesen DMSc); Department & in the SYNTAX trial, only 705 patients with left main coronary \\
\hline $\begin{array}{l}\text { of Cardiology, Odense } \\
\text { University Hospital, Odense, }\end{array}$ & artery disease were included. Although, the randomised trials \\
\hline Denmark (L O Jensen DMSc); & suggested that $\mathrm{PCI}$ was a valid alternative to $\mathrm{CABG}$, we found a \\
\hline Department of Cardiology, & need for further documentation with a large randomised trial. \\
\hline Vilnius University Hospital, & dvalue \\
\hline $\begin{array}{r}\text { Vilnius, Lithuania } \\
\text { (G Kalinauskas PhD); }\end{array}$ & idded value of this study \\
\hline 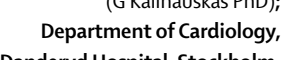 & \\
\hline
\end{tabular}

Danderyd Hospital, Stockholm, Sweden (R B A Linder FESC); Heart and Lung Center, Helsinki University Hospital, Helsinki, Finland (M Pentikainen PhD); Department of Cardiology, Oslo University Hospital,

Rikshospitalet, Oslo, Norway (A Hervold MD); Oxford Heart Centre, Oxford, UK (Prof A Banning FRCP); Department of Cardiology, Freeman Hospital and Institute of Cellular Medicine, Newcastle, UK (Prof A Zaman FRCP); Heart and Lung Centre, New Cross Hospital, Wolverhampton, UK (J Cotton MD); Department of Cardiology, Haukeland University Hospital, Bergen, Norway (E Eriksen MD); Department of Cardiology, East

Tallinn Hospital, Tallinn,

Estonia (S Margus MD); Department of Clinical Epidemiology, Aarhus University Hospital, Aarhus, Denmark, and the Department of Health Research and Policy

(Epidemiology), Stanford University, Stanford, CA, USA (Professor HT Sørensen DMSc); Department of Cardiac Surgery,

Aarhus University Hospital,

Skejby, Aarhus, Denmark (P H Nielsen MD); Department of Cardiology, Karolinska University Hospital, Huddinge, Stockholm, Sweden (M Corbascio PhD); Department of Cardiac Surgery, Oulu University Hospital, Finland (V Anttila PhD); and Sussex Cardiac Centre, Brighton and Sussex University Hospital, Brighton, UK (UTrivedi MD, D Hildick-Smith MD) compared with CABG in revascularisation of 1200 patients with unprotected left main coronary artery stenosis.

\section{Methods}

\section{Study design and participants}

The Nordic-Baltic-British left main revascularisation study (NOBLE) is a prospective, randomised, open-label, non-inferiority trial, done at 36 hospitals in Latvia, Estonia, Lithuania, Germany, Norway, Sweden, Finland, the UK, and Denmark.

A local interventional cardiologist and a cardiac surgeon at each site prospectively assessed eligible patients with left main coronary artery disease. Inclusion criteria for study enrolment were stable angina pectoris, unstable angina pectoris, or acute coronary syndrome, together with a lesion with visually assessed stenosis diameter $\geq 50 \%$ or fractional flow reserve $\leq 0.80$ in the left main coronary artery ostium, mid-shaft, or bifurcation, with no more than three additional noncomplex lesions. Complex lesions were defined as chronic total occlusions: bifurcation lesions requiring two stent techniques or lesions with calcified or tortuous vessel morphology. Participant exclusion criteria were ST-elevation infarction within $24 \mathrm{~h}$, being considered too high risk for CABG or PCI, or expected survival of less than 1 year. Patients were enrolled in the study by site investigators or designated staff. A screening log was maintained in five centres, which recruited 506 of the 1201 patients. All enrolled patients provided written informed consent. The protocol and consent forms were consistent with Good Clinical Practice, the Declaration of Helsinki, and all relevant regulations. The study was approved by The Central Denmark Region Committees on Health Research Ethics, and by national or local ethics committees for the individual sites as appropriate, and by the Danish Data Protection Agency. with left main coronary artery disease undergoing $\mathrm{PCI}$ compared with CABG are consistent with previous randomised studies. With 1201 patients included in our study the increased rates of major adverse cardiac or cerebrovascular events (MACCE) associated with $\mathrm{PCI}$ beyond 1 year became significant, and confirm findings from a meta-analysis also showing increased MACCE after PCl at 5 years. In contrast with the SYNTAX trial, our study suggested that patients with left main coronary artery disease had inferior outcome after $\mathrm{PCl}$ compared with $\mathrm{CABG}$, irrespective of coronary lesion complexity assessed with the SYNTAX score.

Implications of all the available evidence Despite similar mortality, the 5-year risk of MACCE is higher after $\mathrm{PCl}$ compared with CABG for treatment of unprotected left main coronary artery disease.

\section{Randomisation and masking}

Patients for whom it was determined that equivalent revascularisation could be achieved with CABG or PCI were randomly assigned (1:1) to undergo either treatment. Randomisation was done by a web-based computer randomisation system (Trialpartner, random allocation sequence generated by Jakob Hjort, Institute of Clinical Medicine, Aarhus University, Aarhus, Denmark) in permutated blocks by country and centre with stratification by gender, presence of a distal left main coronary artery bifurcation lesion, and presence of diabetes. Patients were assigned to the allocated treatment according to randomisation by the local research team. However, the treating surgeon or cardiologist could over-rule the assignment if the patient was found not to be eligible for the allocated treatment or if the patient refused to undergo the allocated treatment. The study was not blinded.

\section{Procedures}

Patients were treated with the intention of achieving complete revascularisation of all vessels with significant lesions. In the PCI group, ostial and mid-shaft lesions were treated with a single stent. Distal bifurcation lesions could be treated with two-stent techniques, preferably the culotte technique. Mini crush, T-stenting, V-stenting, or a single-stent strategy could be used if appropriate to lesion morphology and the PCI's operator experience. High-pressure post-dilatation after stent implantation was recommended for all cases. Final kissing balloon dilatation was encouraged after main-vessel-only stenting and was mandatory when a two-stent technique was used. Intravascular ultrasound was strongly recommended pre-stent and post-stent deployment. Use of drug-eluting stents was mandatory. In March, 2010, after treatment of 73 patients with PCI, the Biolimus-eluting stent 
(Biomatrix Flex, Biosensors, Morges, Switzerland) became the recommended study stent.

Patients randomly assigned to the CABG group were treated according to present clinical practice. The left internal mammary artery was recommended for revascularisation of the left anterior descending coronary artery, whenever feasible. For other lesion locations, saphenous venous grafts, free arterial grafts, or the right internal mammary artery could be used.

After the index procedure, patients were treated according to local practice. Treatment included 75-150 mg of aspirin lifelong. In both groups, patients with acute coronary syndrome received $75 \mathrm{mg}$ clopidogrel daily for 12 months. All patients in the PCI groups also received $75 \mathrm{mg}$ clopidogrel daily for 12 months. Prasugrel or ticagrelor could be substituted for clopidogrel at the discretion of the PCI operator.

Diagnostic angiograms were reviewed at an independent core laboratory (European Cardiovascular Research Center [CERC], Massy, France) who were blinded to the assigned treatment. Diagnostic angiograms were scored according to the SYNTAX I score algorithm at both the recruitment sites and the core laboratory. ${ }^{13}$ An independent clinical events committee consisting of cardiologists and a cardiac surgeon adjudicated all possible events concerning cause of death, stroke, myocardial infarction, revascularisation, graft occlusion, and stent thrombosis (see appendix for list of members). The study was overseen by an independent Data and Safety Monitoring Board, which received information on clinical events (see appendix for list of members).

\section{Outcomes}

The primary endpoint was a composite of major adverse cardiac and cerebrovascular events (MACCE; death from any cause, non-procedural myocardial infarction, ${ }^{14}$ repeat revascularisation, or stroke). The main hypothesis was non-inferiority of PCI to CABG, assessed as the lower limit of the $95 \% \mathrm{CI}$ of the hazard ratio (HR) of PCI to CABG, not exceeding 1.35 assessed at median 3 years follow-up.

The original primary endpoint was assessment of non-inferiority of PCI to CABG assessed by MACCE at full 2 years follow-up. However, because of low MACCE event rates, the primary endpoint assessment was January, 2015, changed to a median follow-up including all MACCE endpoints occurring during 5 years of followup and the primary endpoint was assessed when the originally stipulated 275 primary endpoint events were reached. September, 2015, it was forecasted that the 275 events would not be reached within full 5 years of follow-up, and the primary endpoint assessment was changed to median 3 years (appendix).

Other clinical endpoints were the individual components of the primary MACCE endpoint, definite stent thrombosis, and symptomatic graft occlusion. Procedural myocardial infarctions were documented (post hoc). Repeat revascularisations were categorised as target lesion revascularisation, left main coronary artery target lesion revascularisation, or de-novo lesion revascularisation. Functional class was reported as the maximum New York Heart Association (NYHA) score and chest pain was reported as the maximum Canadian Cardiovascular Society (CCS) score at up to 5 years follow-up.

\section{Statistical analyses}

The sample size calculation was based on estimated occurrence of the composite primary endpoint of MACCE after mean follow-up of 2 years. An HR of $1 \cdot 36$, comparing PCI and CABG at 1 year, was derived from the SYNTAX trial, ${ }^{11-12}$ and translated into $30 \%$ of PCI patients and $23 \%$ of CABG patients experiencing MACCE after 2 years of follow-up. An HR of 1.35 was defined accordingly as the clinically acceptable non-inferiority limit not to be exceeded by the one-sided 95\% CI. This

See Online for appendix

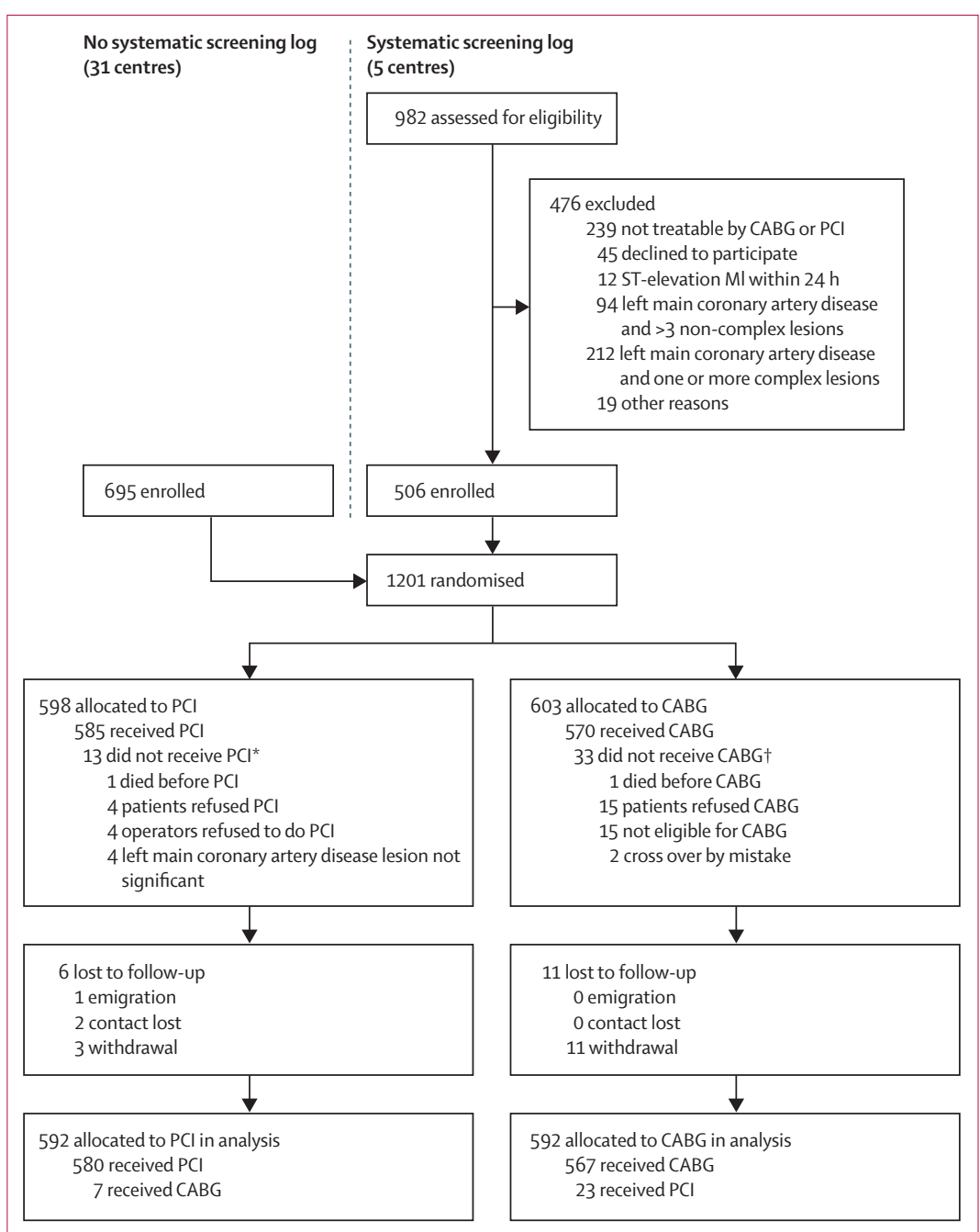

Figure 1: Flow chart

$\mathrm{CABG}=$ coronary artery bypass grafting. $\mathrm{PCl}=$ percutaneous coronary intervention. $\mathrm{Ml}=$ myocardial infarction. *Six received CABG as index treatment and seven received no index treatment. $\uparrow 26$ received $\mathrm{PCl}$ as index treatment and seven received no index treatment. 


\begin{tabular}{|c|c|c|c|}
\hline & $\mathrm{PCl}(\mathrm{n}=592)$ & CABG $(n=592)$ & $\mathrm{p}$ value \\
\hline Age (years) & $66.2(9.9)$ & $66.2(9 \cdot 4)$ & 0.91 \\
\hline Women & $116(20 \%)$ & $140(24 \%)$ & 0.09 \\
\hline Body-mass index $\left(\mathrm{kg} / \mathrm{m}^{2}\right)$ & $27 \cdot 9(4 \cdot 5)$ & $28 \cdot 1(4 \cdot 4)$ & 0.53 \\
\hline Diabetes type 1 or type 2 & $86(15 \%)$ & $90(15 \%)$ & 0.94 \\
\hline $\begin{array}{l}\text { Family history of ischaemic } \\
\text { heart disease }\end{array}$ & $321(58 \%)$ & $307(56 \%)$ & 0.45 \\
\hline Statin treatment & $482(82 \%)$ & $464(78 \%)$ & 0.17 \\
\hline Hypertension & $386(65 \%)$ & $389(66 \%)$ & 0.91 \\
\hline Active smoking & $108(19 \%)$ & $127(22 \%)$ & 0.18 \\
\hline Previous PCI & $116(20 \%)$ & $118(20 \%)$ & 0.90 \\
\hline Previous CABG & $4(1 \%)$ & $2(<1 \%)$ & 0.41 \\
\hline Ejection fraction & $60 \%$ (IQR 55-65) & 60 (IQR 52-64) & 0.27 \\
\hline \multicolumn{4}{|l|}{ NYHA class } \\
\hline 1 & $244(53 \%)$ & $195(43 \%)$ & .. \\
\hline II & $135(29 \cdot 6 \%)$ & $150(33 \%)$ & .. \\
\hline III & $57(13 \%)$ & $77(17 \%)$ & .. \\
\hline IV & $23(5 \%)$ & $33(7 \%)$ & 0.0120 \\
\hline EUROSCORE & 2 (IQR 2-4) & 2 (IQR 2-4) & 0.18 \\
\hline SYNTAX score & $22 \cdot 5(7 \cdot 5)$ & $22.4(8.0)$ & 0.74 \\
\hline \multicolumn{4}{|l|}{ Indication } \\
\hline Stable angina pectoris & $486(82 \%)$ & $491(83 \%)$ & 0.66 \\
\hline Acute coronary syndrome & $106(18 \%)$ & $100(17 \%)$ & 0.66 \\
\hline Lesions to be treated ( $[\mathrm{IQR}]$ ) & $2(1-3)$ & $2(2-3)$ & $<0.0001$ \\
\hline Distal LMCA lesion & $477(81 \%)$ & $482(81 \%)$ & 0.77 \\
\hline
\end{tabular}

corresponded to a total of 275 events, with 1200 patients, 600 in each treatment group, required to detect noninferiority of PCI to CABG at 2 years follow-up. Because the total number of events could not be reached within the full 5 year follow-up period for MACCE, the primary endpoint was assessed at a median of 3 years of follow-up (see appendix for details of sample size calculation and changes to the primary endpoint reporting).

The intention-to-treat principle was used in the analysis if not specified otherwise. Continuous variables were reported as mean (SD) and compared by $t$ test if they followed a Gaussian distribution. Continuous variables not following a Gaussian distribution were reported as their median value (IQR) and compared using the Mann-Whitney test. Binary variables were reported as counts and percentages, and baseline and in-hospital differences between the two groups were assessed with the $\chi^{2}$ or Fisher's exact test if a cell value was lower than 5. Follow-up began at randomisation. In the analysis of individual endpoints, follow-up continued until the date of a clinical endpoint event, death, emigration, or 5 years after randomisation, whichever occurred first. All patients were followed for at least 1 year. Clinical outcomes occurring during the 30 days after the index procedure and at 12 months were presented with risk differences (RDs) and compared using the log-rank test. Extended follow-up to 5 years was reported using 5 year Kaplan-Meier estimates and HRs with $95 \%$ CIs computed on unadjusted Cox regression analysis. Cumulative rates of MACCE were stratified into three groups based on the core laboratory SYNTAX score (low: $\leq 22$; intermediate: 23-32; and high: $\geq 33$ ), and presented by Kaplan-Meier curves. A p value of less than 0.05 was considered significant. All analyses were done using Stata 12 . The trial was registered with ISRCTN87206264 and ClinicalTrials.gov identifier: NCT01496651.

\section{Role of the funding source}

Aarhus University Hospital was the main sponsor of the trial. Biosensors provided an institutional research grant for the trial but had no role in the study design; in the collection, analysis, and interpretation of the data; in the writing of this report; or in the decision to submit the paper for publication. The corresponding author, NRH, and HTS had full access to all the data in the study and together with the writing group (appendix) had the final responsibility for the decision to submit for publication. We designed the study, wrote the manuscript, and vouch for the completeness and accuracy of data collection and analysis.

\section{Results}

1201 patients were enrolled from Dec 9, 2008, to Jan 21, 2015, in 36 centres. 14 patients withdrew consent, three were lost to follow-up, and 1184 were included in the analysis (592 patients in each group; figure 1). Patients were followed for at least 1 year and extended follow-up was available for a median of $3 \cdot 1$ years (IQR $2 \cdot 0-5 \cdot 0$ ). Follow-up for the primary endpoint was continued until May 1, 2016, and was available for $533(90 \%)$ and 532 (90\%) of the study population at 2 years, $412(69 \%)$ and $400(67 \%)$ at 3 years, $308(52 \%)$ and $293(50 \%)$ at 4 years, and 224 $(38 \%)$ and $208(35 \%)$ at 5 years in the PCI and CABG group respectively, corresponding to $69 \%$ of the total study follow-up completed (4094 of 5920 death-adjusted patientyears of follow-up).

Mean ages were 66.2 years (SD 9.9) in the PCI group and 66.2 years $(9 \cdot 4)$ in the CABG group $(\mathrm{p}=0 \cdot 91)$, there were 116 women (20\%) in the PCI group and $140(24 \%)$ in the CABG group $(\mathrm{p}=0 \cdot 0902)$, and 86 patients $(15 \%)$ had diabetes in the PCI group compared with 90 (15\%) in the CABG group $(\mathrm{p}=0.94)$. The logistic EUROSCORE was 2 (IQR 2-4; $=0 \cdot 19$ ) in both groups and the SYNTAX scores were 22.4 (SD 7.8) in the PCI group and 22.3 $(7 \cdot 4)(p=0 \cdot 706)$ in the CABG group. The procedure indication was stable angina pectoris or silent ischaemia in $486(82 \%)$ of 592 patients in the PCI group and $491(83 \%)$ of 591 in the CABG group ( $\mathrm{p}=0 \cdot 44)$. Distal left main coronary artery disease was present in 477 (81\%) of 592 patients in the PCI group and 482 (81\%) of 592 patients in the CABG group $(\mathrm{p}=0 \cdot 71)$. Additional characteristics of the study population are provided in table 1. 
Among PCI-treated patients in the per-protocol analysis group (appendix), 312 (54\%) of 580 had isolated treatment for left main coronary artery disease, 191 (33\%) of 580 had one additional lesion treated, and 55 (9\%) of 580 had two additional lesions treated. Treatment for left main coronary artery disease involved the bifurcation in $508(88 \%)$ of 579 patients in the PCI group, and two-stent techniques were applied in 176 (35\%) of 508 patients with left main coronary artery bifurcation treatments. A first-generation drug-eluting stent was implanted in the left main coronary artery in $11 \%$ of PCI cases. The nominal diameter of stents in the left main coronary artery was $4.0 \mathrm{~mm}$ (IQR $4 \cdot 0-4 \cdot 5$ ), and was inflated to $18 \mathrm{~atm}$ (IQR 16-20). Kissing balloon inflation was done in 277 (55\%) of 508 patients, and any ostial circumflex postdilatation was done in 399 (79\%) of 508 of left main coronary artery bifurcation treatments. Complete revascularisation was achieved in 543 (92\%) of 592 patients treated with PCI. Intravascular ultrasound of the left main coronary artery was done pre-PCI in 270 (47\%) and postPCI in 430 (74\%) of 580 PCI-treated patients.

CABG was done with the on-pump technique in $476(84 \%)$ of 564 patients, 526 (93\%) of 563 patients underwent arterial grafting of the left anterior descending artery, and 480 (86\%) of 561 underwent left internal mammary artery plus venous grafting. Grafting with the right internal mammary artery was done in $44(8 \%)$ patients. The number of grafts per patient were one in $23(4 \%)$ patients, two in 294 (52\%) patients, three in $220(39 \%)$ patients, four in $25(4 \%)$ patients, and five in three $(<1 \%)$ of patients (appendix).

Kaplan-Meier estimates of MACCE by intention-totreat after 5 years were $29 \%$ (121 events) for PCI and $19 \%$ (81 events) for CABG (figure 2). The HR was 1.48 (95\% CI 1.11-1.96), exceeding the limit for non-inferiority $(1 \cdot 35)$, and was significant for superiority of CABG compared with PCI ( $\mathrm{p}=0$-0066). Notably, 1 year rates of MACCE in the two groups were the same (42 [7\%] vs 42 [7\%]; RD 0.0, 95\% CI $-2 \cdot 9$ to $2 \cdot 9, \mathrm{p}=1 \cdot 00$ ). Outcome by actual treatment was 120 events $(28 \%)$ in the PCI group versus 78 events in the CABG group (19\%; HR $1 \cdot 55,95 \%$ CI $1 \cdot 18-2 \cdot 04, \mathrm{p}=0 \cdot 0015)$.

Table 2 shows 5 year risk estimates comparing $\mathrm{PCI}$ with CABG for all-cause mortality, non-procedural myocardial infarction, stroke (all were ischaemic), total repeat revascularisation, repeat revascularisation of the left main coronary artery, and de-novo lesion revascularisation during follow-up. Maximum NYHA score at up to 5 years follow-up was I in $57 \%$ and $54 \%$, II in $37 \%$ and $36 \%$, III in $5 \%$ and $10 \%$, and $\mathrm{V}$ in $1 \%$ and $0.2 \%$ in PCI-treated and CABG-treated patients $(\mathrm{p}=0 \cdot 011)$, respectively. Canadian Cardiovascular Society class score at up to 5 years follow-up was 0 in $42 \%$ and $50 \%, 1$ in $41 \%$ and $35 \%, 2$ in $14 \%$ and $13 \%, 3$ in $3 \%$ and $2 \%$, and 4 in $1 \%$ and $1 \%(\mathrm{p}=0 \cdot 093)$ in PCI and CABG, respectively.

Table 3 shows rates of outcomes, comparing the PCI group with the CABG group, during the 30 days following

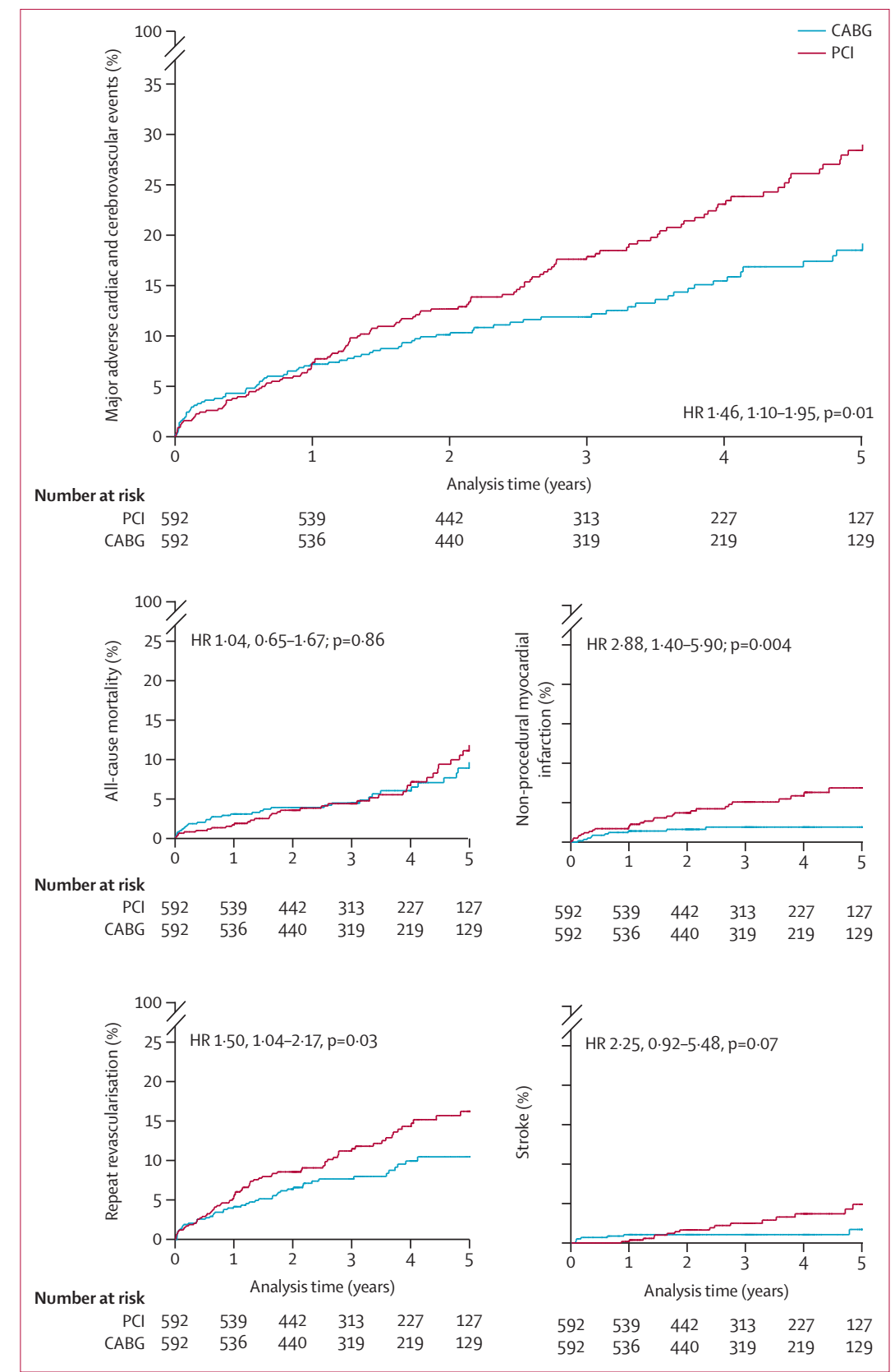

Figure 2: Outcomes according to intention to treat

$\mathrm{CABG}=$ coronary artery bypass grafting. $\mathrm{PCl}=$ percutaneous coronary intervention

the index procedure for procedural myocardial infarction (assessable in 296 [50\%] of 592 and 238 [40\%] of 592 patients), reoperation for bleeding, blood transfusion, surgery for a sternum infection, and surgery to address access site complications. The duration of the index treatment admission was 2 days (IQR 1-4) for PCI and 9 days (IQR 7-13; $\mathrm{p}<0 \cdot 0001$ ) for CABG. Table 4 shows 1 year clinical outcomes.

Comparing the PCI group with the CABG group, 5 year Kaplan-Meier estimates for MACCE in the SYNTAX score subgroups were as follows: low score (1-22) in 57 (30\%) of 


\begin{tabular}{|c|c|c|c|c|}
\hline & $\mathrm{PCl}(\mathrm{n}=592)$ & CABG $(n=592)$ & Hazard ratio $(95 \% \mathrm{Cl})$ & p value \\
\hline MACCE & $29 \%(121)$ & $19 \%(81)$ & $1.48(1.11-1.96)$ & 0.0066 \\
\hline All-cause mortality & $12 \%(36)$ & $9 \%(33)$ & $1.07(0.67-1.72)$ & 0.77 \\
\hline Cardiac death & $3 \%(14)$ & $3 \%(15)$ & $0.93(0.45-1.92)$ & 0.84 \\
\hline Vascular death & $1 \%(2)$ & $<1 \%(1)$ & $1.96(0 \cdot 18-21 \cdot 66)$ & 0.55 \\
\hline $\begin{array}{l}\text { Non-procedural myocardial } \\
\text { infarction }\end{array}$ & $7 \%(29)$ & $2 \%(10)$ & $2.88(1.40-5.90)$ & 0.0040 \\
\hline Revascularisation (total) & $16 \%(71)$ & $10 \%(47)$ & $1.50(1.04-2.17)$ & 0.032 \\
\hline Revascularisation with $\mathrm{PCl}$ & $13 \%(56)$ & $10 \%(45)$ & $1.23(0.83-1.83)$ & 0.29 \\
\hline Revascularisation with CABG & $4 \%$ (19) & $<1 \%(2)$ & $9 \cdot 40(2 \cdot 19-40 \cdot 38)$ & 0.0026 \\
\hline Target lesion revascularisation & $12 \%(50)$ & $8 \%(36)$ & $1 \cdot 38(0.90-2 \cdot 12)$ & 0.14 \\
\hline Target LMCA revascularisation & $10 \%(41)$ & $9 \%(33)$ & $1.23(0.78-1.94)$ & 0.37 \\
\hline De-novo lesion revascularisation* & $6 \%(24)$ & $3 \%(11)$ & $2 \cdot 34(1 \cdot 16-4 \cdot 74)$ & 0.018 \\
\hline $\begin{array}{l}\text { Symptomatic graft occlusion or } \\
\text { definite stent thrombosis }\end{array}$ & $3 \%(9)$ & $4 \%(15)$ & $0.59(0.26-1 \cdot 36)$ & 0.22 \\
\hline Possible stent thrombosis & $1 \%(4)$ & 0 &.. & .. \\
\hline Probable stent thrombosis & $<1 \%(2)$ & 0 &.. &.. \\
\hline Stroke & $5 \%(16)$ & $2 \%(7)$ & $2.25(0.93-5.48)$ & 0.073 \\
\hline
\end{tabular}

\begin{tabular}{|c|c|c|c|c|}
\hline & $\mathrm{PCl}(\mathrm{n}=592)$ & CABG $(n=592)$ & Risk difference $(95 \% \mathrm{Cl})$ & $\mathrm{p}$ value \\
\hline All-cause mortality & $2(<1 \%)$ & $7(1 \%)$ & $-0.8 \%(-1.8$ to 0.1$)$ & 0.09 \\
\hline Cardiac death & $2(<1 \%)$ & $7(1 \%)$ & $-0.8 \%(-1.8$ to 0.1$)$ & 0.09 \\
\hline Vascular death & 0 & 0 & $0 \%$ & 1.00 \\
\hline $\begin{array}{l}\text { Procedural myocardial } \\
\text { infarction* }\end{array}$ & $16 / 296(5 \%)$ & $16 / 238(7 \%)$ & $-1 \cdot 3 \%(-5 \cdot 4$ to $2 \cdot 8)$ & 0.52 \\
\hline $\begin{array}{l}\text { Non-procedure-related } \\
\text { myocardial infarction }\end{array}$ & $3(1 \%)$ & 0 & $0.5 \%(-0.06$ to 1.1$)$ & 0.08 \\
\hline $\begin{array}{l}\text { Definite stent thrombosis or } \\
\text { symptomatic graft occlusion }\end{array}$ & $1(<1 \%)$ & $2(<1 \%)$ & $-0.1 \%(-0.7$ to 0.4$)$ & 0.56 \\
\hline Repeat revascularisation & $7(1 \%)$ & $10(2 \%)$ & $-0.5 \%(-1.8$ to 0.8$)$ & 0.46 \\
\hline Stroke & 0 & $4(<1 \%)$ & $-0.7 \%(-1.3$ to -0.01$)$ & 0.04 \\
\hline Reoperation for bleeding & $1(<1 \%)$ & $23(4 \%)$ & $-3 \cdot 7 \%(-5 \cdot 3$ to $-2 \cdot 1)$ & $<0.0001$ \\
\hline Blood transfusion & $11(2 \%)$ & $150(28 \%)$ & $-25 \cdot 4 \%(-29 \cdot 3$ to $-21 \cdot 5)$ & $<0.0001$ \\
\hline Surgery for sternum infection & 0 & $3(<1 \%)$ & $-0.5 \%(-1.1$ to 0.07$)$ & 0.08 \\
\hline $\begin{array}{l}\text { Surgery for access site } \\
\text { complications }\end{array}$ & $2(<1 \%)$ & $4(1 \%)$ & $0.3 \%(-1.2$ to 0.5$)$ & 0.41 \\
\hline $\begin{array}{l}\text { CT-verified pulmonary } \\
\text { embolus }\end{array}$ & $1(<1 \%)$ & $1(<1 \%)$ & $0.0 \%(-0.4$ to 0.9$)$ & 0.99 \\
\hline $\begin{array}{l}\text { Duration of index treatment } \\
\text { admission (days) }\end{array}$ & $2(1-4)$ & $9(7-13)$ & .. & $<0.0001$ \\
\hline
\end{tabular}

Data are $\mathrm{n}(\%)$, or median (IQR) unless otherwise specified. $\mathrm{CABG}=$ coronary artery bypass grafting. $\mathrm{PCl}=$ percutaneous coronary intervention. *Assessable in 534 (45\%) of patients.

Table 3: Outcomes between index procedure and 30 days of follow-up by treatment group

297 versus 33 (16\%) of 316 (HR $1 \cdot 88,95 \%$ CI $1 \cdot 23-2 \cdot 89$, $\mathrm{p}=0 \cdot 0031 ; 613$ [52\%] of 1184 patients in study population); intermediate score $(23-32)$ in $52(27 \%)$ of 249 versus $37(22 \%)$ of $220(1 \cdot 16,0 \cdot 76-1 \cdot 78, \mathrm{p}=0 \cdot 48 ; 469$ [40\%] 1184 of study population); and high score (>32) in $12(33 \%)$ of 46 versus $11(24 \%)$ of $56(1 \cdot 41,0 \cdot 62-3 \cdot 20, p=0 \cdot 41 ; 02$ [9\%] of 1184 patients in study population; figure 3$)$.

\section{Discussion}

The EXCEL and NOBLE studies are the largest international randomised studies so far, comparing PCI and CABG in the treatment of left main coronary artery disease. ${ }^{15}$ The key findings of the NOBLE study are that CABG was better than PCI for the composite endpoint of MACCE; all-cause mortality was similar between the two groups; non-procedural myocardial infarction and need for repeat revascularisation were increased after PCI; a higher rate of stroke was observed in the CABG group after 30 days than in the PCI group, but an unexpected, numerically higher rate of stroke was found in PCI-treated patients in 5 year estimates; maximum angina pectoris score was higher after PCI at up to 5 years follow-up; the differences in outcomes were seen mainly after 1 year of follow-up; and the SYNTAX score was not associated with MACCE after PCI.

The composite primary MACCE endpoints were similar in NOBLE and the SYNTAX trial except that NOBLE did not include peri-procedural myocardial infarction. We found no difference in large peri-procedural myocardial infarctions between PCI and CABG in NOBLE, and similar to NOBLE, no difference was observed at 1 year in the SYNTAX trial comparing the PCI group with the CABG group (MACCE: $13.7 \%$ vs $15 \cdot 8 \%, \mathrm{p}=0 \cdot 44) .{ }^{12}$ At 5 year follow-up in the SYNTAX trial, the MACCE rate was higher in the PCI group than in the CABG group $(36 \cdot 9 \%$ vs $31 \cdot 0 \%, \mathrm{p}=0 \cdot 12) .{ }^{16} \mathrm{~A}$ metaanalysis $^{17}$ of the SYNTAX left main coronary artery subgroup and PRECOMBAT showed that PCI was associated with significantly higher MACCE than CABG after 5 years $(28 \cdot 3 \%$ vs $23 \cdot 0 \%, \mathrm{p}=0 \cdot 045)$, as confirmed by the NOBLE trial. 
Our findings of similar mortality but higher rates of myocardial infarction and repeat revascularisation in patients undergoing PCI than those undergoing CABG are consistent with previous major studies of coronary revascularisation in patients with left main coronary artery disease. ${ }^{1-4,16-17}$ The low mortality after treatment in both groups shows that modern revascularisation techniques and adjunctive therapy can lead to excellent survival in stable patients with left main coronary artery disease. Nevertheless, the increased rates of non-procedural myocardial infarction, repeat revascularisation, and stroke associated with PCI are important considerations in selecting optimum treatment for individual patients.

The reason for the increase in myocardial infarctions during follow-up after PCI might be multifactorial because both target lesion-related myocardial infarctions and de-novo lesion myocardial infarctions were contributory. The main advantage of CABG might be bypassing of longlesion segments by grafting, which protects, to a greater extent, against target lesion myocardial infarctions and proximal de-novo lesion myocardial infarctions. Although the increased rate of myocardial infarctions after PCI did not translate into differences in cardiac deaths, all reported myocardial infarctions were diagnosed during symptomdriven hospital admissions, signalling a disadvantage for the patient.

Maximum angina pectoris score was higher after PCI than after $\mathrm{CABG}$, probably contributing to the increased revascularisation rates in the PCI group. Increased revascularisation rates after PCI compared with CABG are consistent with previous publications on both left main coronary artery disease stenting ${ }^{1-9}$ and three-vessel coronary artery disease stenting., ${ }^{418}$ Although restenosis of drug-eluting stents has diminished over time with the introduction of high-pressure deployment, ${ }^{19}$ use of intravascular ultrasound, ${ }^{20}$ and improved stent design, ${ }^{21}$ it remains a weakness of PCI for treatment of left main coronary artery disease. This might again reflect the superiority of bypassing the lesion territory as well as segments with potentially progressive disease. Accordingly, we found a small difference in target left main coronary artery revascularisation, but more than two-times increase in the need for de-novo lesion revascularisation in the PCI group compared with the CABG group during follow-up. Repeat revascularisation was done mainly with PCI, but an estimated $4.4 \%$ of $\mathrm{PCI}$-treated patients required revascularisation with CABG during the 5 years of follow-up. Because no angiographic follow-up was done, rates of asymptomatic graft or stent failure are unknown.

Stroke rates were remarkably low in this study, especially during the first 30 days post-procedure. During follow-up, stroke rates in the surgical cohort were almost static, whereas in the PCI group, the very low early procedural stroke rate $(0.0 \%)$ gradually increased over time to an estimated $4.9 \%$ at 5 years. These findings contrast with previous studies, which have tended to

\begin{tabular}{|c|c|c|c|c|}
\hline & $\mathrm{PCl}(\mathrm{n}=592)$ & $\begin{array}{l}\text { CABG } \\
(n=592)\end{array}$ & Risk difference $(95 \% \mathrm{Cl})$ & $p$ value \\
\hline MACCE & $42(7 \%)$ & $42(7 \%)$ & $0.0 \%(-2.9$ to 2.9$)$ & 1.00 \\
\hline All-cause mortality & $9(2 \%)$ & $17(3 \%)$ & $-1 \cdot 3 \%(-3 \cdot 0$ to $0 \cdot 3)$ & 0.11 \\
\hline Cardiac death & $8(1 \%)$ & $13(2 \%)$ & $-0.8 \%(-2.3$ to 0.6$)$ & 0.27 \\
\hline Vascular death & 0 & $1(<1 \%)$ & $0.1(-0.1$ to 0.3$)$ & 0.32 \\
\hline $\begin{array}{l}\text { Non-procedural myocardial } \\
\text { infaction }\end{array}$ & $11(2 \%)$ & $8(1 \%)$ & $0.5 \%(-0.9$ to 1.9$)$ & 0.49 \\
\hline Revascularisation (total) & $32(5 \%)$ & $24(4 \%)$ & $1 \cdot 4 \%(-1 \cdot 1$ to $3 \cdot 8)$ & 0.27 \\
\hline $\begin{array}{l}\text { Symptomatic graft occlusion or } \\
\text { definite stent thrombosis }\end{array}$ & $2(<1) \%$ & $7(1 \%)$ & $-0.8 \%(-1.8$ to 0.1$)$ & 0.09 \\
\hline Stroke & $2(<1 \%)$ & $6(1 \%)$ & $-0.7 \%(-1.6$ to 0.3$)$ & 0.16 \\
\hline \multicolumn{5}{|c|}{$\begin{array}{l}\text { Data are } n(\%) \text { unless otherwise specified. } \mathrm{MACCE}=\text { major adverse cardiac or cerebrovascular events. } \mathrm{CABG}=\text { coronary } \\
\text { artery bypass grafting. } \mathrm{PCl}=\text { percutaneous coronary intervention. }\end{array}$} \\
\hline
\end{tabular}

show a higher stroke rate for CABG, persisting at longterm follow-up in the 5 year report of the SYNTAX left main coronary artery trial, whereas the differences in stroke rates were limiting at longer follow-up in the other randomised trials. All strokes were ischaemic, with no clear explanation for the rate among PCI-treated patients. The strokes in the PCI group mainly occurred after 1 year, coinciding with termination of dual antiplatelet inhibition treatment. However, the low number of strokes and the late separation of the stroke event curves do not exclude that this finding was due to chance.

The SYNTAX score was not associated with adverse outcomes after PCI in contrast with the SYNTAX study. ${ }^{11,16}$ The unexpected finding of a substantially better outcome after CABG in the low SYNTAX score group could be the result of the fact that $87 \%$ of PCI treatments involved left main coronary artery bifurcation which is known to predict worse outcome. This might therefore represent a limitation of the SYNTAX score for treatment selection in patients with left main coronary artery disease. The clinical use of the SYNTAX score might be better in patients with multivessel disease, based on whom the score was developed.

30-day outcomes were noteworthy. The death rate in patients treated with PCI was only $0.3 \%$, compared with $1.2 \%$ in patients undergoing CABG. Only $1.2 \%$ of PCI-treated patients and $1.7 \%$ of CABG-treated patients required repeat revascularisation during the first 30 days post-procedure. Disadvantages of CABG manifested during early follow-up, with a $3.9 \%$ reoperation rate for bleeding, a $0 \cdot 5 \%$ reoperation rate for sternum infection, and a $27.5 \%$ rate of blood transfusion. The median hospital admission period ( 2 days for PCI and 9 days for CABG) represented a significant difference between the revascularisation modalities.

Although MACCE was exactly the same for the two treatment groups at 1 year, there was a significant difference in the long-term outcomes between the PCI and CABG groups. This finding suggests that selecting 


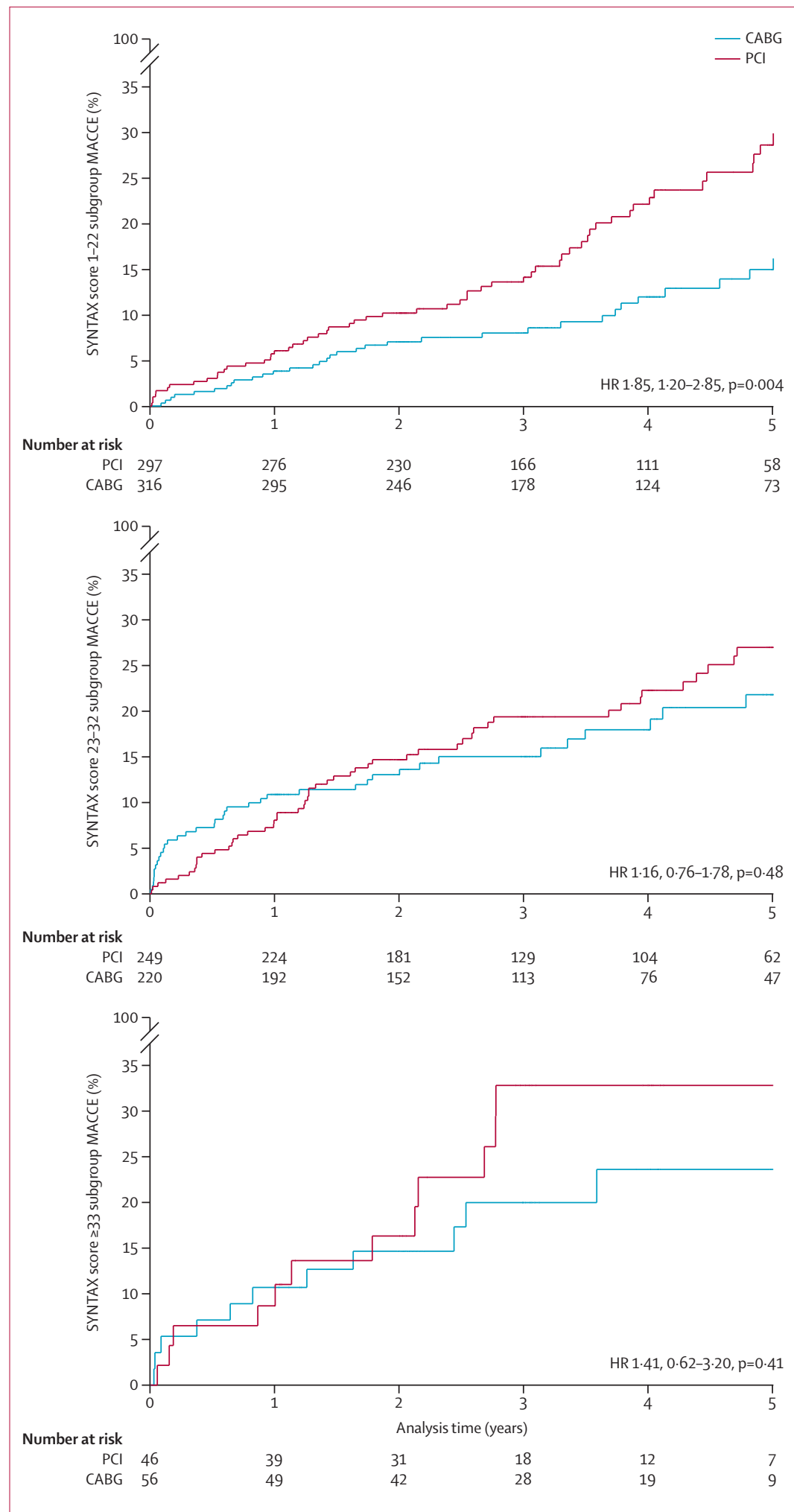

Figure 3: Outcomes by SYNTAX score group

$\mathrm{CABG}=$ coronary artery bypass grafting. $\mathrm{PCl}=$ percutaneous coronary intervention.
PCI over CABG can be justified in patients with reduced life expectancy. However, our data clearly show that the practice of only reporting event rates at 1 year $^{22}$ in PCI revascularisation trials is not reliable for predicting longterm prognosis.

In terms of surgical technique, most CABG-treated patients received one or more arterial grafts. Although high long-term patency of the internal mammary artery is expected, ${ }^{23}$ some vein graft degeneration can be expected beyond 5 years. ${ }^{24}$ We will follow all patients for MACCE for a full 5 years and for all-cause mortality for 10 years.

Among PCI patients, most had bifurcation left main coronary artery involvement, consistent with previous studies. ${ }^{11}$ A single-stent provisional approach was used for two-thirds of patients, and a third underwent dual stenting, chiefly with the culotte technique. The optimum stent implantation technique in left main coronary artery disease is unknown, ${ }^{25}$ but adequate expansion and full lesion coverage are required. ${ }^{26}$ Intravascular ultrasound can be helpful in this regard, but less than half of PCI-treated patients had a pre-PCI intravascular ultrasound assessment and $75 \%$ had a post-PCI intravascular ultrasound assessment. Detailed analysis of the intravascular ultrasound data and stenting techniques could improve our understanding of implantation results in this trial. Most patients with left main coronary artery disease have artery diameters above $4 \mathrm{~mm}$ (average $5.7 \mathrm{~mm}$ ) indicating the requirement for post-dilatation beyond the nominal diameter. ${ }^{27}$ Bench testing of the $3.5 \mathrm{~mm}$ and $4.0 \mathrm{~mm}$ BioMatrix stent (similar platform) showed the ability to expand to $5.9 \mathrm{~mm}^{28}$ Larger left main arteries were possibly excluded by the local cardiac teams. Most patients had post-dilatation of the left main coronary artery, but only half of them had post-dilatation with balloons larger than $4 \mathrm{~mm}$. Stent underexpansion and malapposition in the left main coronary artery might have contributed to the numerically higher target left main coronary artery revascularisations in the PCI group.

The NOBLE results should be generalised with caution and also in particular the SYNTAX stratified results because they are different from the findings of previous studies. The change to the primary endpoint timing is a major limitation of our study, but was carefully considered by investigators and statisticians in response to the low event rates to avoid a vastly underpowered and probably inconclusive primary non-inferiority endpoint reporting. The reporting by Kaplan-Meier estimates could be affected by a change in risk for those entering the study early and late, as will be determined at the full 5 year follow-up. However, the main 5 year Kaplan-Meier outcome estimates in NOBLE are in line with the results presented in the meta-analysis of 5 year outcome in the SYNTAX left main coronary artery disease and PRECOMBAT trials. ${ }^{17}$ Because patients in NOBLE were elective or stabilised, patient results might not be applicable in the acute setting where PCI might be 
preferred over CABG if the anatomy is suitable for PCI. The centres in the trials were selected according to interest in left main coronary artery disease and bifurcation treatment, and CABG might be even better compared to PCI when done in centres with a low volume of left main PCI. A small fraction of patients were treated with first-generation drug-eluting stents and the study stent had a strut thickness above most types of currently used permanent metallic stents. Nevertheless, the study stent is a proven device with good clinical results in general use, ${ }^{29,30}$ and it is therefore uncertain if the applied stent types affects the generalisability of our results.

The primary endpoint of this study clearly favoured surgical revascularisation. However, it was a composite endpoint, and the results might be interpreted in various ways. We saw a slight difference in patients refusing the allocated treatment in favour of PCI and in some patients' view, the need for surgery, the long stay in hospital, the risk of reoperation for bleeding and infection, and a longer recovery time might not be worth the lower risk of repeat revascularisation and myocardial infarction because no difference in all-cause mortality was found.

In conclusion, the NOBLE trial showed that CABG might provide a better clinical outcome for treatment of left main coronary artery disease than PCI.

\section{Contributors}

TM and LT designed the trial and wrote the protocol. Contracts and funding were handled by JFL, LT, EHC, and NRH. Statistical analysis was done by NRH with advice from HTS. The writing committee (MSS, ANJG, IBAM, DH-S, ML, TM, MN, KK, AE, PS, TT, PCE, VA, LT, EHC, $\mathrm{NRH}, \mathrm{PHN}$, and HTS) interpreted results and wrote the report. All authors contributed to implementation of the study, data acquisition, and approved the report for publication.

\section{Declaration of interests}

TM has received grants from Biosensors to the institution during the conduct of the study. NRH received institutional research grants from Biosensors, Abbott, Cordis, Medtronic, Biotronik, Reva Medical, Elixir, and Boston Scientific, and received speaker fees from Boston Scientific, ST Jude Medical, and Terumo. ML received grants from Biosensors during the conduct of the study. MS received personal fees from Edwards Lifesciences, Medtronic, and Boston Scientific, outside the submitted work. AE received personal fees from Biosensors, outside the submitted work. IBAM received grants from Bisosensors during the conduct of the study and other grants from Biosensors and Boston Scientific, outside the submitted work. JR reports grants from Biosensors to his institution, outside the submitted work. LOJ reports grants from Biosensors, Terumo, St Jude Medical, and Biotronik to her institution, and personal fees from Biotronik, outside the submitted work. RBAL reports grants from Biosensors to his institution, outside the submitted work. MP reports grants from Biosensors, during the conduct of the study. AB reports personal fees from Abbott Vascular, Medtronic, and Boston Scientific, outside the submitted work and is partially funded by the NIHR Oxford Biomedical Research Centre. JC reports non-financial support from Biosensors, during the conduct of the study and other from Travel Support Medtronic, outside the submitted work. MN and KK report grants from Biosensors to their institution, during the conduct of the study. JFL reports grants from Boston Scientific, St Jude Medical, Biosensors, Biotronik, and Terumo, outside the submitted work. MM reports grants from Boston Scientific, BioSensors International, and Volcano, outside the submitted work. KO reports grants from Biosensors, during the conduct of the study and personal fees from Biosensors, outside the submitted work. GB reports personal fees from Vascutek Ltd, outside the submitted work. IK reports grants from Biosensors to his institution and personal fees from
AstraZeneca, outside the submitted work. JH reports grants from Biosensors to his institution, during the conduct of the study. DH-S reports other support from BioSensors, during the conduct of the study. EHC reports grants from Biosensors to his institution. TT, ME, HR, GK, AH, AZ, EE, SM, HTS, PHN, SJW, CGH, PS, ANJG, PCE, MC, TKS, OK, UT, VA, OF, LT, and TK declare no competing interests.

\section{Acknowledgments}

We thank the study secretary Helle Bargsteen and study coordinators Pia Stycke Ottosen and Lars Peter Jørgensen (all Aarhus University Hospital, Denmark) for their major contribution during the conduct of the trial. We also thank data manager Jakob Hjort (Aarhus University, Denmark) for his important contribution during all phases of the trial.

\section{References}

1 Buszman PE, Kiesz SR, Bochenek A, et al. Acute and late outcomes of unprotected left main stenting in comparison with surgical revascularisation. J Am Coll Cardiol 2008; 51: 538-45.

2 Ahn JM, Roh JH, Kim YH, et al. Randomized trial of stents versus bypass surgery for left main coronary artery disease: 5-year outcomes of the PRECOMBAT Study. J Am Coll Cardiol 2015; 65: 2198-206.

3 Boudriot E, Thiele H, Walther T, et al. Randomized comparison of percutaneous coronary intervention with sirolimus-eluting stents versus coronary artery bypass grafting in unprotected left main stem stenosis. J Am Coll Cardiol 2011; 57: 538-45.

4 Mohr FW, Morice MC, Kappetein AP, et al. Coronary artery bypass graft surgery versus percutaneous coronary intervention in patients with three-vessel disease and left main coronary disease: 5-year follow-up of the randomised, clinical SYNTAX trial. Lancet 2013; 381: 629-38.

5 Chieffo A, Stankovic G, Bonizzoni E, et al. Early and mid-term results of drug-eluting stent implantation in unprotected left main. Circulation 2005; 111: 791-95.

6 Park SJ, Kim YH, Lee BK, et al. Sirolimus-eluting stent implantation for unprotected left main coronary artery stenosis: comparison with bare metal stent implantation. J Am Coll Cardio 2005; 45: 351-56.

7 Shiomi H, Morimoto T, Furukawa Y, et al. Comparison of percutaneous coronary intervention with coronary artery bypass grafting in unprotected left main coronary artery disease-5-year outcome from CREDO-Kyoto PCI/CABG registry cohort-2. Circ J 2015; 79: 1282-89.

8 Valgimigli M, van Mieghem CA, Ong AT, et al. Short- and long-term clinical outcome after drug-eluting stent implantation for the percutaneous treatment of left main coronary artery disease: insights from the Rapamycin-Eluting and Taxus Stent Evaluated At Rotterdam Cardiology Hospital registries (RESEARCH and T-SEARCH). Circulation 2005; 111: 1383-89.

9 Jang JS, Choi KN, Jin HY, et al. Meta-analysis of three randomized trials and nine observational studies comparing drug-eluting stents versus coronary artery bypass grafting for unprotected left main coronary artery disease. Am J Cardiol 2012; 110: 1411-18.

10 Task Force Members, Montalescot G, Sechtem U, et al. 2013 ESC guidelines on the management of stable coronary artery disease: the Task Force on the management of stable coronary artery disease of the European Society of Cardiology. Eur Heart J 2013; 34: 2949-3003.

11 Serruys PW, Morice MC, Kappetein AP, et al. Percutaneous coronary intervention versus coronary-artery bypass grafting for severe coronary artery disease. N Engl J Med 2009; 360: 961-72.

12 Morice MC, Serruys PW, Kappetein AP, et al. Outcomes in patients with de novo left main disease treated with either percutaneous coronary intervention using paclitaxel-eluting stents or coronary artery bypass graft treatment in the synergy between percutaneous coronary intervention with TAXUS and cardiac surgery (SYNTAX) trial. Circulation 2010; 121: 2645-53.

13 Sianos G, Morel MA, Kappetein AP, et al. The SYNTAX Score: an angiographic tool grading the complexity of coronary artery disease. EuroIntervention 2005; 1: 219-27.

14 Thygesen K, Alpert JS, Jaffe AS, et al. Third universal definition of myocardial infarction. Circulation 2012; 126: 2020-35.

15 Campos CM, Christiansen EH, Stone GW, Serruys PW. The EXCEL and NOBLE trials: similarities, contrasts and future perspectives for left main revascularisation. EuroIntervention 2015 11 (suppl V): V115-19. 
16 Morice MC, Serruys PW, Kappetein AP, et al. Five-year outcomes in patients with left main disease treated with either percutaneous coronary intervention or coronary artery bypass grafting in the synergy between percutaneous coronary intervention with taxus and cardiac surgery trial. Circulation 2014; 129: 2388-94.

17 Cavalcante R, Sotomi Y, Lee CW, et al. Outcomes after percutaneous coronary intervention or bypass surgery in patients with unprotected left main disease. J Am Coll Cardiol 2016; 68: 999-1009.

18 Serruys PW, Onuma Y, Garg S, et al. 5-year clinical outcomes of the ARTS II (Arterial Revascularisation Therapies Study II) of the sirolimus-eluting stent in the treatment of patients with multivessel de novo coronary artery lesions. J Am Coll Cardiol 2010; 55: 1093-101.

19 Nakamura S, Hall P, Gaglione A, et al. High pressure assisted coronary stent implantation accomplished without intravascular ultrasound guidance and subsequent anticoagulation. J Am Coll Cardiol 1997; 29: 21-27.

20 Park SJ, Kim YH, Park DW, et al. Impact of intravascular ultrasound guidance on long-term mortality in stenting for unprotected left main coronary artery stenosis. Circ Cardiovasc Interv 2009; 2: 167-77.

21 Pyxaras SA, Hunziker L, Chieffo A, et al. Long-term clinical outcomes after percutaneous coronary intervention versus coronary artery bypass grafting for acute coronary syndrome from the DELTA registry: a multicentre registry evaluating percutaneous coronary intervention versus coronary artery bypass grafting for left main treatment. EuroIntervention 2016; 12: e623-31.

22 Morice MC, Serruys PW, Sousa JE, et al. A randomized comparison of a sirolimus-eluting stent with a standard stent for coronary revascularisation. $N$ Engl J Med 2002; 346: 1773-80.

23 Goldman S, Zadina K, Moritz T, et al. Long-term patency of saphenous vein and left internal mammary artery grafts after coronary artery bypass surgery: results from a Department of Veterans Affairs Cooperative Study. J Am Coll Cardiol 2004; 44: 2149-56.
24 Campeau L, Enjalbert M, Lesperance J, Bourassa MG, Kwiterovich P,Jr, Wacholder S, Sniderman A. The relation of risk factors to the development of atherosclerosis in saphenous-vein bypass grafts and the progression of disease in the native circulation. A study 10 years after aortocoronary bypass surgery. N Engl J Med 1984; 311: 1329-32.

25 Chen SL, Xu B, Han YL, et al. Clinical outcome after DK crush versus culotte stenting of distal left main bifurcation lesions: the 3-year follow-up results of the DKCRUSH-III Study. JACC Cardiovasc Interv 2015; 8: 1335-42.

26 Kang SJ, Ahn JM, Song H, et al. Comprehensive intravascular ultrasound assessment of stent area and its impact on restenosis and adverse cardiac events in 403 patients with unprotected left main disease. Circ Cardiovasc Interv 2011; 4: 562-69.

27 Shand JA, Sharma D, Hanratty C, et al. A prospective intravascular ultrasound investigation of the necessity for and efficacy of postdilation beyond nominal diameter of 3 current generation DES platforms for the percutaneous treatment of the left main coronary artery. Catheter Cardiovasc Interv 2014; 84: 351-58.

28 Foin N, Sen S, Allegria E, et al. Maximal expansion capacity with current DES platforms: a critical factor for stent selection in the treatment of left main bifurcations? EuroIntervention 2013; 8: 1315-25.

29 Serruys PW, Farooq V, Kalesan B, et al. Improved safety and reduction in stent thrombosis associated with biodegradable polymer-based biolimus-eluting stents versus durable polymer-based sirolimus-eluting stents in patients with coronary artery disease: final 5-year report of the LEADERS (Limus Eluted From A Durable Versus ERodable Stent Coating) randomized, noninferiority trial. JACC Cardiovasc Interv 2013; 6: 777-89.

30 Raungaard B, Jensen LO, Tilsted HH, et al. Zotarolimus-eluting durable-polymer-coated stent versus a biolimus-eluting biodegradable-polymer-coated stent in unselected patients undergoing percutaneous coronary intervention (SORT OUT VI): a randomised non-inferiority trial. Lancet 2015; 385: 1527-35. 